TITLE:

\title{
Slow-positron beamline temperature rise reduction at Kyoto University Research Reactor
}

\section{$\operatorname{AUTHOR}(\mathrm{S})$ :}

Yabuuchi, A.; Naka, R.; Sato, K.; Xu, Q.; Kinomura, A.

\section{CITATION:}

Yabuuchi, A....[et al]. Slow-positron beamline temperature rise reduction at Kyoto University Research Reactor. Nuclear Instruments and Methods in Physics Research Section B: Beam Interactions with Materials and Atoms 2019, 461: 137-141

ISSUE DATE:

2019-12-15

URL:

http://hdl.handle.net/2433/244331

\section{RIGHT:}

(c) 2019. This manuscript version is made available under the CC-BY-NC-ND 4.0 license

http://creativecommons.org/licenses/by-nc-nd/4.0/:; The full-text file will be made open to the public on 15 Decembe 2021 in accordance with publisher's 'Terms and Conditions for Self-Archiving'.; この論文は出版社版でありません。引 用の際には出版社版をご確認ご利用ください。; This is not the published version. Please cite only the published version. 


\title{
Slow-positron beamline temperature rise reduction at Kyoto University Research Reactor
}

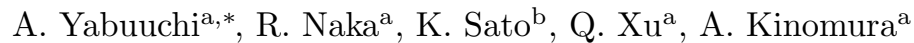 \\ ${ }^{a}$ Institute for Integrated Radiation and Nuclear Science, Kyoto University, Kumatori, Osaka 590-0494, Japan \\ ${ }^{b}$ Graduate School of Science and Engineering, Kagoshima University, Kagoshima 890-0065, Japan
}

\begin{abstract}
Temperature rises of a reactor-based slow-positron beamline at Kyoto University Research Reactor (KUR) were measured during reactor operation and solenoid-coil excitation. During KUR operation at $5 \mathrm{MW}$, the temperature of the top of the beamline reached $300^{\circ} \mathrm{C}$. This temperature which is close to the melting point $\left(321^{\circ} \mathrm{C}\right)$ of $\mathrm{Cd}$ was used to enhance positron generation. On the other hand, the temperature of the flange supporting the beamline was approximately $50^{\circ} \mathrm{C}$ and it was sufficiently low in terms of the strength of the beamline. The temperature of the top of the beamline was successfully reduced to $240^{\circ} \mathrm{C}$ by introducing a He gas flow around the vacuum duct of the beamline. Beamline temperatures calculated using a finite element method were in agreement with measured temperatures. Such calculation is useful for future experiments with longer or irregular KUR operation.
\end{abstract}

Keywords: research reactor, slow positron beam, cadmium, nuclear heating, thermal conductivity, helium gas

\section{Introduction}

Positron annihilation spectroscopy has been widely used to investigate nanometer-scale or atomic-scale vacancy-type defects in various materials such as metals, semiconductors, and ceramics. In particular, energyvariable positron beams (slow positron beam) can be strong analytical tools for advanced materials in the form of thin films, surface layers and ion-irradiated layers $[1,2]$. Positron moderation is required in order to obtain monochromatic positron beams from typical positron sources with broad energy distributions. As the efficiency of positron moderation processes is very low (of the order of $\sim 10^{-4}$ ), intense positron sources are essential for obtaining slow positron beams for actual measurements [1].

Intense positron sources based on electron-positron pair creation have been developed mainly using bremsstrahlung X-rays from electron accelerators or fission gamma-rays from nuclear reactors, while other methods have also been explored using radioisotope positron sources activated by nuclear reactors or ion accelerators [3, 4]. Among these techniques, the reactorbased slow positron beamline developed at the Technical University of Munich achieved the highest positron intensity in the world $[4,5,6]$. Other reactor-based slow positron beamlines developed at the Technical University of Delft and North Carolina State University also have high positron intensities compared with accelerator-based systems $[7,8,9,10]$. Another reactor-based positron beamline is being developed at McMaster University to obtain positron intensity comparable to previously developed beamlines [11].

Relying on this background, a reactor-based slow positron beamline was developed at Kyoto University Research Reactor (KUR) [12, 13]. The beamline is mainly used for material analysis and is open to other researchers as a joint-use experimental facility. The beamline was designed based on the knowledge obtained from previously developed beamlines. As Japan is a country frequently affected by earthquakes, it is necessary to consider certain protective measures. As a countermeasure against earthquakes, source structures were designed and constructed differently from the previously developed systems of other groups. One of the important and specific issues which arose were the temperature rises of the source part of the beamline, which significantly influenced the continuous operation of the slow positron beamline. The following concerns related to the temperature rise of the KUR slow-positron beamline are considered: (1) Overheating caused by a low heat dissipation structure, leading to (2) mechanical-strength reduction of the beamline and (3) Melting of a Cd shroud due to its low melting point $\left(321^{\circ} \mathrm{C}\right)$. This study measured the temperature of the beamline and temperature reduction of the source part, and also calculated the temperature rise in order to solve the above-mentioned issues.

\footnotetext{
${ }^{*}$ Corresponding author

Email address: yabuuchi@rri.kyoto-u.ac.jp (A. Yabuuchi)
} 


\section{Beamline configuration and experimental pro- cedure}

KUR is a light-water tank-type reactor normally operated at $1 \mathrm{MW}$ or $5 \mathrm{MW}$. The core of the reactor consists of $20 \%$-enriched uranium fuel elements and graphite reflector elements. The slow-positron beamline was installed at one of the irradiation holes (B-1 hole) with a diameter of $20 \mathrm{~cm}$. The source part of the beamline consists of a $\mathrm{W}$ converter, two sets of $\mathrm{W}$-mesh moderators (moderator assembly) and an extraction electrode surrounded by a 1mm-thick Cd shroud. The extracted slow positron beam is guided by a magnetic field and transported about $10 \mathrm{~m}$ downstream to a sample position eventually with a diameter of around $10 \mathrm{~mm}$. At the beamline, $1.4 \times 10^{6}$ slow e $^{+} / \mathrm{s}$ and $6.2 \times 10^{6}$ slow $\mathrm{e}^{+} / \mathrm{s}$ are obtained during $1 \mathrm{MW}$ and $5 \mathrm{MW}$ reactor operation, respectively. The reason why the beam intensity during $5 \mathrm{MW}$ operation does not become five times higher compared with that during $1 \mathrm{MW}$ operation is considered to be attributed to an increase in the amount of positronium formation accompanying the temperature rise of a positron moderator [14]. The details regarding the beamline had been already described elsewhere $[12,13]$.

The $\mathrm{Cd}$ shroud was installed to enhance gammaray intensity through ${ }^{113} \mathrm{Cd}(\mathrm{n}, \gamma){ }^{114} \mathrm{Cd}$ reaction in addition to reactor-core gamma-rays. Both neutron-captureinduced prompt gamma-rays emitted from the $\mathrm{Cd}$ shroud and fission gamma-rays emitted from the reactor-core are irradiated to the $\mathrm{W}$ converter to create positrons. ${ }^{113} \mathrm{Cd}$ has a large thermal neutron capture cross-section of 20600 barns and is present in natural cadmium at $12.22 \%$ [15]. Gadolinium is worth considering as another material that has a large thermal neutron capture crosssection and emits prompt gamma-rays. The use of gadolinium in reactor-based positron sources has also been considered by other groups $[16,17]$. However, there was no consensus on whether cadmium or gadolinium is advantageous in enhancing positron creation. Therefore, the KUR slow positron beamline adopted cadmium, which had already been proven in other reactor-based slow positron beamlines $[5,9,10,18,19]$.

It should be noted that the KUR irradiation hole has a double-tube structure consisting of the 'outer sleeve' facing reactor-core water and the 'inner sleeve' installed inside the outer sleeve. A vacuum duct of the beamline with solenoid coils which generate guiding magnetic fields was installed inside the inner sleeve. The B-1 hole has a tripletube structure, as shown in Fig. 1. The core idea of this structure is that the outer sleeve is supposed to be a part of the reactor and the beamline (i.e. vacuum duct) should not be in contact with the outer sleeve even during severe earthquakes that cause mechanical vibration of the top of the beamline. The inner sleeve is supposed to be a kind of backup structure that prevents the beamline from getting into contact with the outer sleeve. As a result, the beamline has a cantilever structure supported by the support flange shown in Fig. 1. The distance from the supporting flange to the top of the beamline is $1478 \mathrm{~mm}$ and the strength of the beamline is important for avoiding contact between the beamline and the inner sleeve. The 4 th tube (guide tube) indicated in Fig. 1 keeps the electric fields along the positron trajectories uniform and its strength has no influence on the vacuum duct.

The gaps between the outer sleeve, the inner sleeve, and the vacuum duct were originally filled with air. To enhance heat dissipation, gas introduction tubes were inserted to fill the gap between the inner sleeve and the vacuum duct with He gas (shaded area of Fig. 1). Initially, only one K-type thermocouple was attached to the top of the beamline to monitor beamline temperature. Additional K-type thermocouples were attached to the base of $\mathrm{W}$-moderator assemblies and the supporting flange to obtain more detailed information on beamline temperature. The thermocouples were installed with cold-junction compensation circuits.

Beamline temperature rises were calculated by a finite element method with Salome-Meca code [20] to understand the heat dissipation processes and to predict temperatures for future experiments under different conditions, such as longer $5 \mathrm{MW}$ operations and irregular reactor operations. The sizes of the outer/inner sleeves, vacuum duct, solenoid coils, and other related structures were included in the calculation model based on the actual design.

\section{Results and discussion}

Temperatures measured by thermocouples at three positions were monitored during a typical KUR operation schedule (1 MW operation for approximately $47 \mathrm{~h}$, followed by $5 \mathrm{MW}$ operation for approximately $6 \mathrm{~h}$ ). Figure 2(a) shows the time dependence of the temperature of the top of the beamline (Top) and the supporting flange (Support). The time of $0 \mathrm{~h}$ corresponds to the beginning of the $1 \mathrm{MW}$ operation. After the operation started, the Top temperature started to increase. At the time around $5 \mathrm{~h}$, the temperature rise almost saturated at approximately $100^{\circ} \mathrm{C}$. At $6 \mathrm{~h}$, the solenoid coils were turned on to generate guiding magnetic fields. Then, the Top temperature started to increase again and saturated at approximately $150^{\circ} \mathrm{C}$ around $11 \mathrm{~h}$. The current of the primary solenoid coil, which significantly affects beamline temperatures, was $3 \mathrm{~A}$ in this case. At the time of $11.5 \mathrm{~h}$, the solenoid coils were turned off. The temperature started to decrease rapidly. On the other hand, the Support temperature did not increase after the KUR operation started but it slightly increased to almost $50^{\circ} \mathrm{C}$ after the solenoid coils were turned on. When the solenoid coils were turned off, the Support temperature started to decrease in the same way as the Top temperature.

The KUR 5 MW operation was performed successively after the $1 \mathrm{MW}$ operation. Figure 2(b) shows the time dependence of the temperature of the top of the beamline (Top) and the supporting flange (Support). The time of 


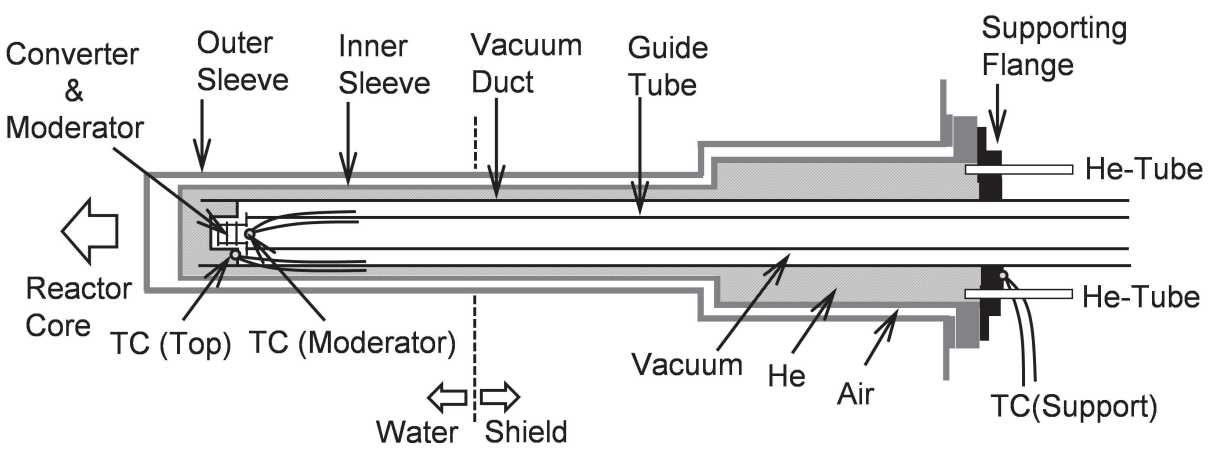

Figure 1: Schematic view of KUR slow-positron beamline source structures. Thermocouples (TC) were attached at three positions (top of the beamline, moderator base, supporting flange).

0 h corresponds to the beginning of 5 MW operation. After this operation began, the Top temperature rapidly started to increase and saturated at nearly $50^{\circ} \mathrm{C}$ around $6 \mathrm{~h}$. The Support temperature did not show any rapid change but it slowly increased to approximately $50^{\circ} \mathrm{C}$ during the operation. The solenoid coils were turned off (see Fig. 2(b)). The 1 MW operation with the use of the solenoid coils suggested that the $5 \mathrm{MW}$ operation with the excitation of the solenoid coils lead to Top temperature increase above $300^{\circ} \mathrm{C}$.

It should be noted that the melting point of $\mathrm{Cd}$ which was used to enhance positron generation is $321^{\circ} \mathrm{C}$. A temperature rise of the $\mathrm{Cd}$ shroud above its melting point may potentially induce the deformation of the $\mathrm{Cd}$ shroud even though the $\mathrm{Cd}$ shroud is sandwiched with an $\mathrm{Al}$ cap. Owing to safety concerns, the positron beam extraction during $5 \mathrm{MW}$ operation with solenoid coils was initially not performed. As it is not effective to stop the positron beam during $5 \mathrm{MW}$ operation, beamline temperature reduction was required.

Owing to their fast radioactive decay, $\mathrm{Al}$ or Al-alloys have been often used for structural materials in high radiation fields. It is well known that heated $\mathrm{Al}$ and Al-alloy lose their strength at relatively lower temperatures compared with stainless steel. Since it is important to know the temperature of the vacuum duct during reactor operation, additional thermocouples were attached to the beamline. The temperature of the supporting flange was approximately $50^{\circ} \mathrm{C}$ even during $5 \mathrm{MW}$ operation, as shown in Fig. 2(b). The vacuum duct is made of an Al-alloy (A5052). According to literature [21], yield strength values of $\mathrm{A} 5052$ alloy at $25^{\circ} \mathrm{C}, 100^{\circ} \mathrm{C}$, and $150^{\circ} \mathrm{C}$ are $90 \mathrm{~N} / \mathrm{mm}^{2}$ for these three temperatures, implying that the strength of the vacuum duct at the supporting flange during $5 \mathrm{MW}$ operation does not change from the strength at room temperature. The additional thermocouple gave important information related to the safety of the beamline.

Heat caused by nuclear heating from reactor radiation (mainly gamma-rays) and joule heating by solenoid coils must be efficiently wasted to surrounding reactorcore water, reactor biological shields or beamline components. The triple-tube structure employed for safety rea- sons may suffer from heat problems. Heat dissipation from the reactor-based positron beamline has been pointed out in previous studies done by other groups $[11,5]$. In the case of the beamline in Munich, the source part of the beamline has a double-tube structure where a Cd cap (shroud) is directly attached inside the outer sleeve that faces reactorcore water. It ensures better cooling of the $\mathrm{Cd}$ cap. The source part of the beamline in Delft has a triple-tube structure (i.e. a combination of an outer tube, an inner tube, and a vacuum duct) but cooling water is inserted between the outer tube and the inner tube to reduce source temperature [22].

It is difficult to use cooling water in the case of the KUR slow-positron beamline. Water cooling was not taken into account in the initial design and thus it required large-scale modifications of the whole system to ensure it would safely handle cooling water. Gas cooling was then considered instead of water cooling, although its efficiency is not as good as water cooling. In addition, the installation of cooling gas lines requires considerable modifications of the source part. Therefore, the possibility of filling the gap between the inner sleeve and the vacuum duct with He gas was examined. In the initial design, air exists in the gaps among the outer sleeve, the inner sleeve, and the vacuum duct. Thermal conductivity of air and He is $0.0316 \mathrm{~W} / \mathrm{mK}$ and $0.166 \mathrm{~W} / \mathrm{mK}$ at $100^{\circ} \mathrm{C}$, respectively. The thermal conductivity of He is nearly one order of magnitude higher than that of air. We expected that the replacement of He with air would increase heat transfer and reduce temperatures of the source part of the beamline. Based on this idea, two gas lines were inserted at the supporting flange in order to introduce a flow of He gas into the gap between the inner sleeve and the vacuum duct, as shown in Fig. 1.

Figure 3 shows temperature profiles of the top of the beamline during KUR operation at $5 \mathrm{MW}$ under three different sets of conditions. The $5 \mathrm{MW}$ operation started after the $1 \mathrm{MW}$ operation. The beginning of $5 \mathrm{MW}$ operation corresponds to $0 \mathrm{~h}$ in Fig. 3. The stopping time of $5 \mathrm{MW}$ operation is slightly different depending on experimental schedules of each run. The temperature profiles without He flow (with air) was the same as that in Fig. 2(b). The temperature increased and started to satu- 

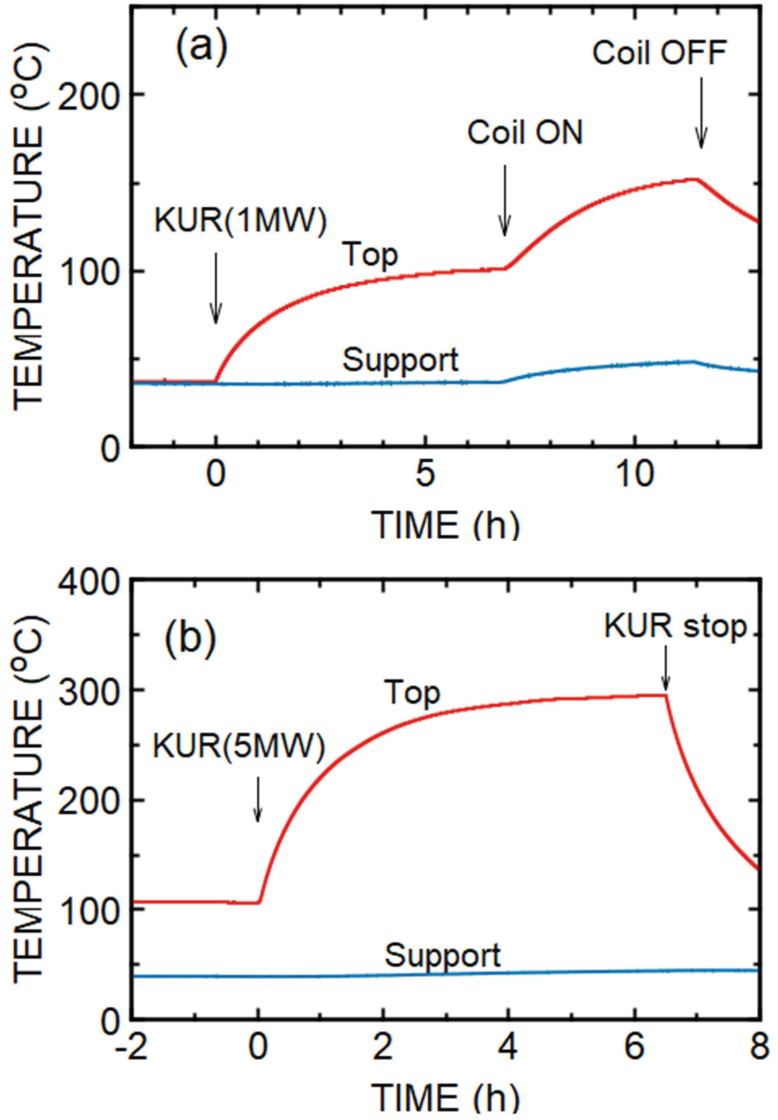

Figure 2: Results of temperature measurements of the top at the KUR slow positron beamline. (a) Temperature rise during $1 \mathrm{MW}$ operation. (b) Temperature rise during $5 \mathrm{MW}$ operation following 1 MW operation.

rate approximately at $300^{\circ} \mathrm{C}$. He gas flow was introduced at $-3 \mathrm{~h}$ (i.e. $3 \mathrm{~h}$ before the $5 \mathrm{MW}$ operation). The flow rate of He was $2 \mathrm{~L} / \mathrm{min}$ (see Fig. 3). Note that the sealing between the inner sleeve and the supporting flange consisted of fitted metal faces so the introduced He gas could escape outside. It turned out that a continuous He gas flow was required and $\mathrm{He}$ gas must be introduced in advance before the $5 \mathrm{MW}$ operation. When the He gas flow of $2 \mathrm{~L} / \mathrm{min}$ was introduced but solenoid coils were not used, the temperature almost saturated and reached $240^{\circ} \mathrm{C}$. When the He gas flow $(2 \mathrm{~L} / \mathrm{min})$ was introduced and solenoid coils were excited, the temperature saturated and reached $251^{\circ} \mathrm{C}$. A current of the primary solenoid coil was $3 \mathrm{~A}$ in this case. After the optimization of coil currents, the current of $3 \mathrm{~A}$ turned out to be sufficient to extract the positron beam from the source. As a result of He gas introduction, the temperature of the top of the beamline was successfully reduced by approximately $50^{\circ} \mathrm{C}$.

Different He flow rates were examined in the range of $0.5-5 \mathrm{~L} / \mathrm{min}$. Flow rates of $1 \mathrm{~L} / \mathrm{min}, 2 \mathrm{~L} / \mathrm{min}$, and $5 \mathrm{~L} / \mathrm{min}$ rendered temperatures below $250^{\circ} \mathrm{C}$ at the end of $5 \mathrm{MW}$ operation without coil excitation, while the temperature slightly increased when the flow rate decreased. A flow rate of $0.5 \mathrm{~L} / \mathrm{min}$ rendered the temperature of approximately

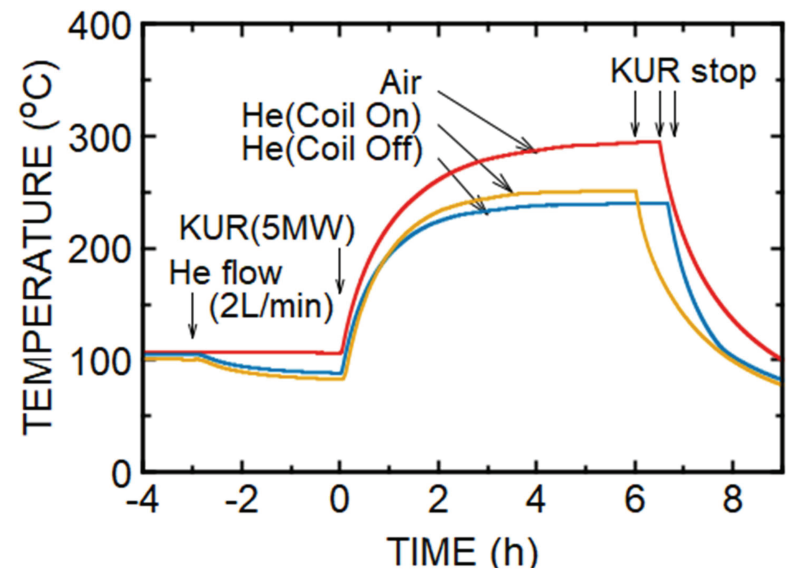

Figure 3: Results of temperature measurements at the top of the KUR slow positron beamline. Temperatures with and without $\mathrm{He}$ flow/coil excitation were compared for $5 \mathrm{MW}$ operation.

$270^{\circ} \mathrm{C}$. All the flow rates examined in this experiment were sufficient to suppress the temperature rise of the top of the beamline.

Another thermocouple was attached to the base of the moderator, as shown in Fig. 1. The maximum temperature of the moderator base in the case of Fig. 2(b) was $379^{\circ} \mathrm{C}$ at the end of $5 \mathrm{MW}$ operation. The moderators were installed inside the vacuum duct without any direct contacts with the vacuum duct and the $\mathrm{Cd}$ shroud. The influence of the moderator temperature on the $\mathrm{Cd}$ shroud was limited except for the heat radiation from the converter and moderators.

Calculation of beamline temperatures was performed by Salome-Meca code to understand the heat dissipation processes and to predict temperatures for future experiments under different conditions, such as longer $5 \mathrm{MW}$ operations and irregular reactor operations. Geometrical parameters of the beamline were included into the calculation model of Salome-Meca together with material parameters (thermal diffusivity and specific heat). The temperature of reactor-core water was assumed to be $50^{\circ} \mathrm{C}$ (typical temperature during KUR operation) as a boundary condition. The temperatures of the reactor biological shield and the supporting flange were assumed to be $45^{\circ} \mathrm{C}$ and $40^{\circ} \mathrm{C}$ as other boundary conditions. Nuclear heating values of $\mathrm{Al}$ and $\mathrm{Cd}$ at the top of the beamline during the $5 \mathrm{MW} \mathrm{KUR} \mathrm{operation} \mathrm{were} \mathrm{assumed} \mathrm{to} \mathrm{be} 0.04 \mathrm{~W} / \mathrm{g}$ and $0.20 \mathrm{~W} / \mathrm{g}$, calculated based on the data from another research reactor [23]. These nuclear-heating values were uniformly applied for the $30 \mathrm{~cm}$ region from the top of the outer sleeve. Since heat radiation cannot be included in the calculation with Salome-Meca code, the heat transfer from the moderator to the vacuum duct through heat radiation was treated as a boundary condition of the constant heat flux. The expression of heat flux $Q$ was defined as

$$
Q=F \sigma\left(T_{1}^{4}-T_{2}^{4}\right),
$$

where $T_{1}$ is the average temperature of the con- 


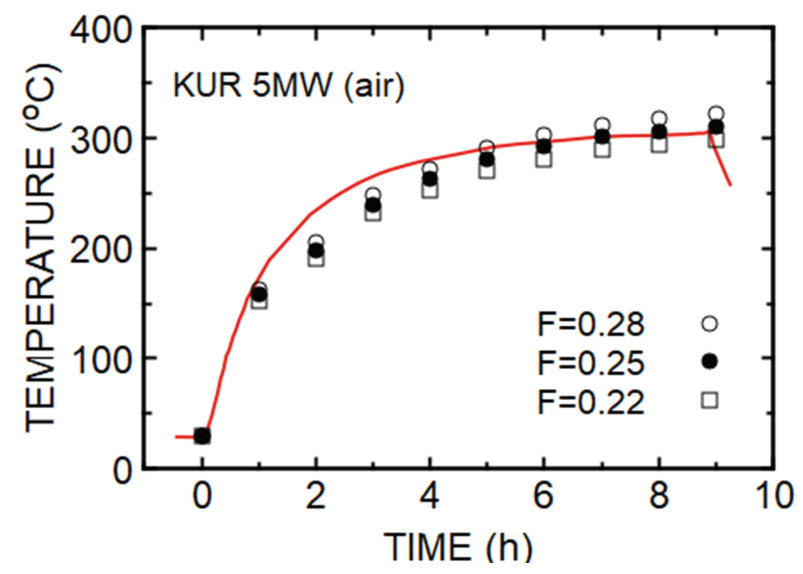

Figure 4: Comparison of the measured temperature and the calculated temperature. Three different geometrical factors $(F)$ were assumed for the calculation. Measurements were performed for $5 \mathrm{MW}$ operation after $1 \mathrm{MW}$ operation with air.

verter/moderator assembly, $T_{2}$ is the temperature of the vacuum duct wall (part of the vacuum duct) facing the converter/moderator assembly, and $\sigma$ is the Stefan-Bolzmann constant. $F$ is the geometrical factor that represents the complex geometry of the converter/moderator assembly and the vacuum-duct wall.

Figure 4 shows the temperature profiles of the top of the beamline during $5 \mathrm{MW}$ operation without $\mathrm{He}$ flow (with air). Open circles, closed circles, and open squares indicate the calculated temperatures assuming three different geometrical factors $(F)$. Calculated values given by these geometrical factors were in good agreement with the measured temperature profile. The calculation assumed the constant heat flux from the converter/moderator assembly for simple approximation, while actual radiative heat transfer strongly depended on temperature, as shown in Eq. (1). Even in spite of this simple approximation, the temperatures after saturation should render better values. Therefore, the geometrical factor $F$ in the range from 0.22 to 0.25 may be appropriate. Indeed, the calculated temperatures with $F=0.25$ for no KUR operation and the solenoid-coil excitation were in agreement with the measured temperature profile (not shown). Figure 4 indicates that the model for the temperature calculation was determined appropriately. This calculation model is useful for future planning of different KUR-operation patterns.

\section{Conclusion}

Slow-positron beamline temperatures on Kyoto University Research Reactor (KUR) were measured by thermocouples attached to the top part of the beamline, moderator base, and supporting flange. The rises in temperature at the top of the beamline were monitored during KUR operation and solenoid-coil excitation. During 5 MW KUR operation, the temperature of the top of the beamline was approximately $300^{\circ} \mathrm{C}$. This temperature was close to the melting point of $\mathrm{Cd}\left(321^{\circ} \mathrm{C}\right)$ which was used to enhance positron generation. The temperature of the supporting flange was approximately $50^{\circ} \mathrm{C}$, which is sufficiently low considering the strength of the Al-alloy used for the beamline. The temperature of the top of the beamline was successfully reduced to $240^{\circ} \mathrm{C}$ by introducing the He gas flow around the vacuum duct of the beamline. The temperature of the top of the beamline was calculated using a finite-element method. The result was in agreement with measured temperatures and it can be used for temperature prediction in various KUR operation patterns.

\section{Acknowledgements}

We are grateful to T. Yoshiie (Kyoto Univ.) for his preliminary discussion before we decided what to do for the cooling of the beamline. We also thank Y. Kuzuya (Kyoto Univ.) for his assistance with the experiments.

\section{References}

[1] P. J. Schultz, K. G. Lynn, Rev. Mod. Phys. 6 (1988) 701.

[2] P. Asoka-Kumar, K. G. Lynn, D. O. Welch, J. Appl. Phys. 76 (1994) 4935.

[3] K. G. Lynn, F. M. Jacobsen, Hyperfine Interact. 89 (1994) 19.

[4] C. Hugenschmidt, Proceedings of the International School of Physics "Enrico Fermi" 174 (2010) 399.

[5] C. Hugenschmidt, G. Kögel, R. Repper, K. Schreckenbach, P. Sperr, B. Straßer, W. Triftshäuser, Nucl. Instrum. Methods Phys. Res., Sect B 192 (2002) 97.

[6] C. Hugenschmidt, C. Piochacz, M. Reiner, K. Schreckenbach, New J. Phys. 14 (2012) 055027.

[7] A. van Veen, F. Labohm, H. Schut, J. de Roode, T. Heijenga, P. Mijnarends, Appl. Surf. Sci. 116 (1997) 39.

[8] A. van Veen, H. Schut, F. Labohm, J. de Roode, Nucl. Instrum. Methods Phys. Res., Sect. A 427 (1999) 266.

[9] A. G. Hathaway, M. Skalsey, W. E. Frieze, R. S. Vallery, D. W. Gidley, A. I. Hawari, J. Xu, Nucl. Instrum. Methods Phys. Res., Sect. A 579 (2007) 538 .

[10] A. I. Hawari, D. W. Gidley, J. Moxom, A. G. Hathaway, S. Mukjerjee, J. Phys.: Conf. Ser. 262 (2011) 012024.

[11] P. Mascher, Presentation in 18th International Conference on Positron Annihilation, (unpublished) (19-24 Aug. 2018).

[12] Q. Xu, K. Sato, T. Yoshiie, T. Sano, H. Kawabe, Y. Nagai, K. Nagumo, K. Inoue, T. Toyama, N. Oshima, A. Kinomura, Y. Shirai, J. Phys.: Conf. Ser. 505 (2014) 012030.

[13] K. Sato, Q. Xu, T. Yoshiie, T. Sano, H. Kawabe, Y. Nagai, K. Nagumo, K. Inoue, T. Toyama, N. Oshima, A. Kinomura, Y. Shirai, Nucl. Instrum. Methods Phys. Res., Sect. B 342 (2015) 104.

[14] A. P. Mills, Jr., Phys. Rev. Lett. 41 (1978) 1828.

[15] Radioisotope Pocket Data Book 11th Edition, The Japan Radioisotope Association, 2016, (in Japanese).

[16] A. G. Hathaway, Design and Testing of a Prototype Slow Positron Beam at the NC State University PULSTAR Reactor, North Carolina State University, 2005, master thesis.

[17] H. G. Priesmeyer, G. Bokuchava, Mater. Sci. Eng. A 437 (2006) 54.

[18] B. Krusche, K. Schreckenbach, Nucl. Instrum. Methods Phys. Res., Sect. A 295 (1990) 155.

[19] G. Triftshäuser, G. Kögel, W. Triftshäuser, M. Springer, B. Strasser, K. Schreckenbach, Appl. Surf. Sci. 116 (1997) 45.

[20] https://www . code-aster.org/.

[21] Aluminum Standards and Data 2013 Metric SI, The Aluminum Association, 1998.

[22] H. Schut, private communication (2016). 
[23] JMTR Irradiation Handbook, Japan Atomic Energy Research Institute, 1987, p. 219, (in Japanese). 